Inquiry

An Interdisciplinary Journal of Philosophy

ISSN: 0020-174X (Print) 1502-3923 (Online) Journal homepage: https://www.tandfonline.com/loi/sinq20

\title{
Etiological information and diminishing justification
}

\section{Paul Silva}

To cite this article: Paul Silva (2018) Etiological information and diminishing justification, Inquiry, 61:2, 115-136, DOI: 10.1080/0020174X.2016.1238779

To link to this article: https://doi.org/10.1080/0020174X.2016.1238779

\section{Published online: 09 Nov 2016.}

$\sqrt{6}$ Submit your article to this journal $\square$

LII Article views: 369

Q View related articles $\sqsubset$

View Crossmark data $₫$ 


\title{
Etiological information and diminishing justification
}

\author{
Paul Silva \\ Department of Philosophy, Monash University, Melbourne, Australia
}

\section{ABSTRACT}

Sometimes it's reasonable to reduce confidence in a proposition in response to gaining etiological information. Suppose, for example, a theist learns that her theism is 'due to' her religious upbringing. There is a clear range of cases where it would be reasonable ( $\approx$ blameless) for her to respond by slightly decreasing her confidence in God's existence. So long as reasonability and justification are distinct, this reasonability claim would appear consistent with the thesis that this kind of etiological information cannot, all by itself, affect one's justification. In what follows, I argue that this is mistaken. For, even if reasonability and justification are distinct, the reasonability of decreasing confidence in response to etiological information must be explained in terms of a decrease in justification. The argument to follow threatens not only the stronger thesis that etiological information never defeats justification but the substantially weaker thesis, advocated by various authors, that justification is defeated by etiological information in only a limited range of circumstances. I go on to show how the arguments en route to this conclusion have much wider epistemological ramifications.
\end{abstract}

ARTICLE HISTORY Received 26 March 2016; Accepted 30 August 2016

KEYWORDS Defeaters; etiology; justification; rationality; debunking arguments

\section{The etiological challenge to belief}

Each of our beliefs has an associated etiological story. These stories involve reference to the events, times, places, people, etc. that played a causal role in bringing about the particular beliefs we have. These etiological explanations for our beliefs serve as the backdrop to a different kind of story, a story that explains why our beliefs are (or are not) epistemically justified. To be sure, these two kinds of stories can be connected. Sometimes learning about the etiology of one's belief can improve one's epistemic position. One might, for example, learn that the fact that $P$ caused one's belief that $P$. If so, one thereby learns that one's belief was responsive to reality in a way that ensures the truth of one's belief. Clearly, this would typically enhance 
one's justification for believing P. Conversely, one might learn that some fact incompatible with $\mathrm{P}$ caused one to believe P. Since this is just a way of learning that one has a false belief in $\mathrm{P}$, it is a way of losing justification to believe $P$. What is distinctive of this sort of etiological information is that it entails the truth or falsehood of one's beliefs.

Relatively little of the etiological information we gather about our beliefs is like this, neither entailing that our beliefs are true nor entailing that they're false. Moreover, relatively little of the etiological information we gather about our beliefs has any impact on their justification. Your hunger may have caused you to open the food cupboard and form beliefs about its contents, but learning that your hunger played that particular causal role has no impact on whether or not you have justification to believe that there are, say, cookies in the cupboard. The vast majority of non-entailing etiological information is epistemically irrelevant.

Yet, as many have observed, some non-entailing etiological information seems epistemically relevant. ${ }^{1}$ Consider the following case:

\section{RELIGIOUS BELIEF}

Reggie believes that God exists. His reasons for believing it involve the testimony of those he's grown up around (who claim to have had profound religious experiences of God) and some philosophical arguments. Reggie has encountered many unbelievers, and has shared his reasons for his beliefs with them. But the unbelievers are unmoved. Now, Reggie recognizes a clear trend: those moved by his reasons (or reasons like his) are typically those who have grown up in religious communities where religious beliefs like his are prevalent, encouraged, and otherwise favorably regarded. In contrast, those unmoved by such reasons are typically those who have grown up in irreligious communities or communities of different religious persuasions. In this way, Reggie comes to know that his particular upbringing is (partially) causally responsible for his belief in God's existence and that had he grown up in one of these other communities he would not believe that God exists even if he were exposed to the same evidence. ${ }^{2}$

Examples like this can be multiplied, involving moral, political, and philosophical beliefs. ${ }^{3}$

What is troubling about such cases is that one gains etiological information which indicates that one's belief in P was brought about in a way that was sensitive to factors that are disconnected from whether or not $\mathrm{P}$ is true. Although it is difficult to give a precise account of the nature of the relevant

\footnotetext{
${ }^{1}$ Cohen (2000), Sher (2001), Street (2006), Schoenfield (2013), Elga (2008), Schellenberg (2007), Davis (2009), and Ballantyne (2012).

${ }^{2}$ Assume that Reggie has no particular reason to think his community has been ignoring any relevant evidence or is in some epistemically inferior position vis-a-vis these other communities. Assume also that Reggie has never encountered an unbeliever who could point out problems with his theistic arguments that he didn't have a reasonable response for.

${ }^{3}$ See footnote 1 for references to further examples.
} 
disconnection, two core features are commonly noted. ${ }^{4}$ First, having a belief with a disconnected etiology has to do with the evidential irrelevance of certain causal influences on one's belief. After all, we typically will not cite facts about our upbringing which have exercised a causal influence on our beliefs as evidence that our beliefs are true for the simple reason that such facts are typically evidentially irrelevant. Second, having a belief with a disconnected etiology has to do with the following counterfactual claim being true of the causal influences on one's beliefs: even if one were exposed to the same evidence, one would lack their (degree of) belief if those causal influences were absent. For present purposes, we can treat these two conditions as both necessary and sufficient for a belief having a disconnected etiology, or a 'd-etiology' for short. Thus, d-etiological information is information that indicates these two conditions are satisfied.

Importantly, d-etiological information does not entail epistemic difficulties. For there can be further information that neutralizes any worries d-etiological information threatened to raise. One might have reason to think that their belief's particular d-etiology makes it even more likely to be true. In such a case one should not only retain, but strengthen their belief. There are surely further pieces of information we could imagine acquiring which would halt any worries arising from d-etiological information. But the question I'm concerned with is whether or not d-etiological information can defeat justification when further neutralizing information is absent, as it is in the case of Reggie.

The present issue has a clear connection with the currently thriving evolutionary debunking literature, where a central epistemological question being addressed concerns the extent to which information about the evolutionary etiology of our moral beliefs defeats knowledge and justification for our moral beliefs. This is a question about the extent to which a specific kind of d-etiological information defeats a specific range of beliefs. In contrast, we are here addressing a much more general question: can d-etiological information about any belief defeat justification for that belief? ${ }^{5}$

White (2010) has offered a negative answer to that question, arguing that d-etiological information never defeats justification. Others - e.g. Schoenfield (2013) and Elga (2008) - have only allowed d-etiological information

\footnotetext{
${ }^{4}$ In addition to the references in footnote 1 see White (2010), Schoenfield (2013), Schechter (2008), and Elga (2008) who each draw attention to these points.

${ }^{5}$ There are other epistemological worries that have a central role in the evolutionary debunking literature. For example, whether or not a realist conception of the nature of moral facts would allow for moral knowledge. This is a distinct issue from the one I'm addressing here. For more on that see Clarke-Doane (forthcoming).
} 
to defeat justification in a limited range of circumstances. ${ }^{6}$ After I give the argument against White's view (Section 3), I will show how it can be generalized to afflict Schoenfield and Elga's views (Section 4).

Let us first focus on White's (2010) thesis:

J-Immunity: Gaining d-etiological information about one's belief that $\mathrm{P}$ cannot, all by itself, defeat one's justification to believe that P. ${ }^{7}$

Several remarks are in order. First, in what follows it will be helpful to keep in mind the distinction between propositional and doxastic justification, which marks the difference between having all-things-considered justification to believe $P$ versus having an all-things-considered justified belief in $\mathrm{P}^{8}$ Only when it's necessary for clarity will I explicitly employ the 'propositional/doxastic' terminology.

Second, here and throughout, I will be thinking of our course-grained attitudes of belief, disbelief, and suspension in terms of degrees of belief (= credences, confidences). So, when I express ideas in terms of the corsegrained attitudes it is just for ease of expression. Whenever I do not specify a degree of belief I will always intend the implicit degree of belief to be high, i.e. somewhere well-above .5.

Third, defeating one's justification for their belief in $\mathrm{P}$ will be taken to be a matter of decreasing the degree of belief (or range of degrees of belief) one has justification to have in P. ${ }^{9}$

Fourth, for simplicity, gaining d-etiological information about one's belief in $\mathrm{P}$ will be a matter of coming to know that one's belief in $\mathrm{P}$ has a d-etiology.

Fifth, I'm only concerned with whether or not non-entailing d-etiological information can defeat justification. Entailing d-etiological information is a unique sort of etiological information. The fact that sort of information might affect justification would be unsurprising, and it wouldn't clearly have any implications concerning the epistemic impact of non-entailing d-etiological information.

\footnotetext{
${ }^{6}$ Plantinga (2000) has also argued for something similar. But his arguments are narrowly focused on whether or not theistic belief can be defeated by d-etiological information. His answer is that theism cannot be defeated so long as it's true. This too is challenged in what follows.

${ }^{7}$ The phrasing of this thesis is not White's, but it is equivalent to the conclusion White draws in his (2010) paper.

${ }^{8}$ The key difference being that propositional justification to believe $\mathrm{P}$ does not entail that a subject has a belief in P. For convenience, I will assume the traditional view that having a doxastically justified belief in $\mathrm{P}$ is just a matter of having a belief in $\mathrm{P}$ that is based on one's source of propositional justification to believe P. See Alston (1989), Feldman and Conee (1985), and Pollock and Cruz (1999).

${ }^{9}$ At a minimum, a decrease in a range requires a downward shift in its upper bound whether or not the lower bound is affected.
} 
Six, I'm only concerned with whether or not d-etiological information can defeat justification all by itself. ${ }^{10}$ For the most part, this 'all by itself' qualification will be left implicit in subsequent discussion.

Finally, notice that if J-Immunity holds, then the following holds as well:

JJ-Immunity: Gaining d-etiological information about one's belief that $\mathrm{P}$ cannot,

all by itself, defeat one's justification to believe <that one has justification to believe $\mathrm{P}>.^{11}$

The basic idea is that if d-etiological information cannot defeat one's justification for the first-order claim that $\mathrm{P}$, then it cannot defeat one's justification for the higher order claim $<$ that one has justification to believe $\mathrm{P}>$ either. For it's unclear how d-etiological information concerning one's belief in P should have the effect of defeating one's justification to believe the higher order claim <that one has justification to believe $P>$ while leaving one's justification to believe P intact (as implied by J-Immunity). For d-etiological information concerning one's belief in $P$ typically isn't information about one's higher-order belief <that one has justification to believe $\mathrm{P}>$. One might not have any higher order belief. Even if one did, they remain distinct beliefs in distinct propositions, and they can have very different etiologies as well as very different sources of justification. ${ }^{12}$ Given this, it's hard to see what motivation there could be to think that detiological information never affects one's justification for their first-order beliefs which are their subject matter, but it does affect one's justification for the corresponding higher order beliefs. So, unless a coherent explanation can be produced for thinking otherwise, we should endorse the following: if J-Immunity is true then so is JJ-Immunity. However it's worth noting that, although I think this implication is right and it simplifies the argument to follow, the core argument could be made without it. ${ }^{13}$

Much of the resistance to J-Immunity stems from reflection on concrete cases where it seems like d-etiological information does have an impact on justification. ${ }^{14}$ This is not problematic in itself, but it can lead to a kind

\footnotetext{
${ }^{10}$ To illustrate, suppose one's d-etiological information came by way of information about peer disagreement, and assume that information about peer disagreement defeats justification. Gaining d-etiological information in that way would lead to defeat of justification if information about peer disagreement all by itself defeats justification. But the resulting defeat is not something that gaining d-etiological information would have brought about all by itself.

${ }^{11}$ Throughout, '<...>' are used just as a visual cue for when a higher-order claim is at issue.

${ }^{12}$ For instance, one may believe that a cat is on the mat because of their perceptual experience as of a cat on the mat, but one may believe <that one has justification to believe that a cat is on the mat $>$ because a broad array of epistemologists are present and have asserted one's present perceptual experience is a source of justification. The higher order belief is justified by testimony, while the first-order belief is justified by perceptual experience.

${ }^{13}$ See footnote 32 .

${ }^{14}$ Cohen (2000), Schechter (2008), Sher (2001), Ballantyne (2012), and Vavova (forthcoming).
} 
of dialectical stalemate. For, as White has shown, it can be hard to see (a) how d-etiological information could be allowed to defeat justification without it leading to unacceptable skeptical consequences; and, relatedly, it can be hard to specify (b) what plausible epistemic principles explain the defeating force of d-etiological information. A virtue of the argument to follow is that it does not rely on concrete cases where it seems like $d$ etiological information does have an impact on justification. Rather it takes J-Immunity for granted and shows that doing so helps yield a reductio against J-Immunity. Thus, the argument to follow will not be as susceptible to objections grounded in the difficulty of specifying (a) and (b).

\section{Reasonability and defeat}

If J-Immunity is correct, then one's justification does not decrease just as a result of gaining d-etiological information. But even so, people have a tendency to treat d-etiological information as if it defeated justification. They do this by decreasing, if sometimes only briefly and to a mild extent, their degree of belief in $\mathrm{P}$ upon learning (or seeming to learn) that their belief in $\mathrm{P}$ has a d-etiology. ${ }^{15}$ This tendency to reduce one's confidence in response to d-etiological information is further evinced by the ease with which people transition from thoughts about their beliefs having a d-etiology to questions about whether or not one should continue to hold their beliefs. Similarly, it's also exhibited in the apparent legitimacy of epistemic challenges grounded in d-etiological information. For example, being told that you only believe in anthropogenic climate change because you grew up in a certain political environment has an epistemic bite, feeling like it demands that you be less confident in your belief or else supply additional justification for it. Moreover, this tendency makes it utterly unsurprising that Reggie, or someone in a similar position, might decrease their confidence in God's existence in response to gaining detiological information.

Plainly, people have a tendency to treat d-etiological information as if decreasing their confidence were an appropriate response. So we must ask after the normative standing of such decreased confidence.

A guiding thought should be that at least sometimes there is something epistemically positive to say about those who reduce their confidence in light of d-etiological information. Call such people Reducers. Even if their reduction in confidence isn't justified, it's not as if d-etiological information

\footnotetext{
${ }^{15}$ I have only anecdotal evidence for this in my own case and in the case of others I've talked to. See the references in footnotes 1 and 4 for further anecdotal evidence.
} 
was an obviously epistemically irrelevant consideration. If it were, there just wouldn't be an interesting question about the epistemic impact of d-etiological information. Indeed, if there was absolutely nothing epistemically positive to say about Reducers, then White's (2010) conclusion that d-etiological information has no epistemic impact would seem trivial and unsurprising. But it is far from that. So if J-Immunity is correct, the question is what positive epistemic assessment can be made with respect to those who reduce their confidence in response to d-etiological information.

If J-Immunity is right, then justification isn't the positive epistemic status that Reducers typically have since J-Immunity indicates that justification is immune to d-etiological information. ${ }^{16}$ But this is fine since there are positive epistemic properties other than justification we can appeal to in order to explain what's epistemically positive about Reducers. For justification is a matter of epistemic permissibility, and our inventory of positive epistemic statuses is not exhausted by that notion. ${ }^{17}$ The most obvious positive epistemic quality that applies to, at least many, Reducers is blamelessness. Other things being equal, in cases where agents reduce their confidence in response to d-etiological information, they are acting in an epistemically blameless manner. There are different ways of being epistemically blameless, and one way involves being innocently misled about what factors are epistemically relevant. For, as is commonly pointed out, not all apparent epistemic reasons need be genuine epistemic reasons. ${ }^{18}$ Indeed, if J-Immunity is true, this is exactly how we ought to understand what happens when Reducers reduce their confidence in response to detiological information. For J-Immunity says that d-etiological information cannot, all by itself, defeat one's propositional justification; put differently, $J$-Immunity indicates that d-etiological information concerning one's belief in $\mathrm{P}$ is not a genuine epistemic reason that has any bearing on how one should respond to $P$. So in that sense d-etiological information fails to be a

\footnotetext{
${ }^{16}$ Permissivism is, roughly, the thesis that there can be a range of degrees of belief that one can take towards a proposition (Schoenfield 2013). Lest one thinks permissivism can provide an easy explanation for how the behavior of Reducers could be acceptable, just focus on cases where one's existing belief resided at the lower bound of justified credences and where one just slightly decreased their confidence beyond this lower bound in response to d-etiological information.

${ }^{17}$ The dominant view of justification is one that identifies it with permissibility, i.e. the property of being either optional or obligatory. As Wedgwood $(2012,274)$ puts it '...to say that a belief is justified is to say no more than that it is permissible...' See also Berker (2013), Goldman (1986, 59), Ginet (2005), Littlejohn $(2012,157)$, Lord (forthcoming), and Pollock and Cruz $(1999,123)$. But whether or not this is the best way to explicate the notion, all that matters is that justification remain distinct from blamelessness.

${ }^{18}$ Merely apparent epistemic reasons are non-genuine epistemic reasons that appear to one to be genuine epistemic reasons. Examples of merely apparent reasons are easiest to illustrate on externalist theories of justification (cf. Goldman 1988; Littlejohn forthcoming a). But even internalists have made space for blamelessness in the absence of justification due to the presence of merely apparent reasons (cf. Pryor 2001, 117; Wedgwood 2002, 351). For a lengthy defense of the idea that apparent epistemic reasons needn't be genuine epistemic reasons see Sylvan (2015b) and Littlejohn (forthcoming a).
} 
genuine epistemically relevant reason for altering one's doxastic attitudes. Thus such information can be, at best, a merely apparent epistemic reason; a reason that can make one blameless in responding to it, but a reason that nevertheless fails to affect one's propositional justification all by itself. ${ }^{19}$

There is another way of being blameless that is relevant. Although it is widely assumed that one can be blameless without having justification, ${ }^{20}$ justification and blamelessness do not always come apart. On the standard view of doxastic justification, one has a doxastically justified belief in $\mathrm{P}$ only if (a) one has undefeated propositional justification to believe $P$, and (b) one's belief in $\mathrm{P}$ is based on that which affords one propositional justification to believe P. If condition (a) is met, then one is epistemically permitted to believe $\mathrm{P}$. If condition ( $b$ ) is met, one believes $\mathrm{P}$ because or on the basis of that which affords one justification to believe P. All together, this is tantamount to claiming that one is believing the right thing for the right (epistemic) reasons. If one does that, it's difficult to see what grounds there could be for claiming that one is blameworthy for believing what they do. ${ }^{21}$

There are other ways of being blameless that are presently irrelevant. ${ }^{22}$ So let us use the term 'reasonable' to refer to agents who are blameless in believing what they do because they are responding to apparent epistemic reasons, regardless of whether those reasons are in fact genuine epistemic reasons. When those reasons are genuine epistemic reasons a thinker will be both blameless and doxastically justified. When those reasons are merely apparent epistemic reasons a thinker will only be blameless. I think this should be regarded not just as a stipulative use of the term 'reasonable' but as a partial explication of our ordinary (or at least a common) notion of reasonability (excusability, understandability). But nothing will turn on whether or not my use of the term 'reasonable' is to be regarded as more than a stipulative use. ${ }^{23}$

\footnotetext{
${ }^{19}$ Does having an apparent reason $\mathrm{R}$ demand that one believe $\mathrm{R}$ is a genuine epistemic reason? Not unless one wishes to invite objectionable overintellectualization constraints on the possession of reasons. See Sylvan (2015a, 2015b). See also Reynolds (2013) for defense of the idea that the appearance of knowledge doesn't even require the concept knowledge, much less beliefs involving it.

${ }^{20}$ Alston (1989, 145), Goldman (1988), Boghossian (2008, 259), Feldman and Conee (1985, 17), Pryor (2001, 14-17), Smithies (2012, 280), Wedgwood (2002, 351), Sylvan (2015b), and Littlejohn (2012, forthcoming a).

${ }^{21}$ So Boghossian $(2008,270)$ appears correct in claiming that 'being [doxastically] justified is, at least in part, a matter of being epistemically blameless'.

${ }^{22}$ One such way of being blameless involves a loss of one's agency, e.g. the sort of loss endured by one whose beliefs result from strange pills, brainwashing, psychosis, and so forth. Other things being equal, one cannot be properly blamed in such cases.

${ }^{23}$ This account of reasonability is related to Littlejohn's (forthcoming a) notion of excusability/rationality and Sylvan's (2015b) notion of substantive rationality. Both authors deny that these normative statuses can be identified with justification.
} 
So even if J-Immunity is true, and thus Reducers' reduction of confidence isn't always justified, Reducers clearly can be reasonable (because they are blameless) in their particular response to d-etiological information, which appears to them to be epistemically relevant. Let's cement this thought in the following way:

$R$-Decrease: Other things being equal, if (a) $\mathrm{S}$ 's degree of belief in $\mathrm{P}$ was justified prior to gaining d-etiological information, and (b) $\mathrm{S}$ slightly reduced her degree of belief in $\mathrm{P}$ just in response to gaining that d-etiological information, then $\mathrm{S}^{\prime} \mathrm{S}$ decreased degree of belief in $\mathrm{P}$ is reasonable. ${ }^{24}$

It is important to think about the epistemic impact of gaining d-etiological information concerning one's belief that $P$ that we take one's prior epistemic position with respect to $P$ into account. For this reason (a) specifies that the prior condition is one where a Reducer's degree of belief is justified. Additionally, (b) says that the only decreases in confidence that are guaranteed to be reasonable are slight decreases. The reason for this is that sometimes drastic reductions in confidence will be clearly unreasonable responses to d-etiological information. But it is quite plausible that slight reductions are reasonable. (How slight? I leave it to the reader to supply an answer they find acceptable.)

The 'other things being equal' qualification is to accommodate factors that could potentially crop up in connection with d-etiological information and compromise the reasonability of believing $\mathrm{P}$ to only a slightly diminished degree. For instance, upon gaining d-etiological information one might have also obtained conclusive evidence that $P$ is false. This would certainly have the effect of compromising the reasonability of only slightly decreasing one's confidence in P. Doubtless, there are other ways for a Reducer to fail to be reasonable due to the addition of further factors. I intend the 'other things being equal' clause to screen off those cases. For there are clearly a subset of cases, like Reggie's, where a slight reduction in confidence upon gaining d-etiological information is indeed a reasonable response because it seems like epistemically relevant information.

Above I argued on the basis of a widely shared intuition that, other things equal, it is reasonable for thinkers to decrease confidence in response to detiological information. I've not sought to explain that fact. This is because it seems to be a shared presupposition among all parties to this debate. No one I know of has argued that R-Decrease (or any similar thesis) is false

\footnotetext{
${ }^{24}$ It has been suggested to me that one must have a belief about the epistemic relevance of d-etiological information for a reduction in confidence in response to it to be reasonable. But this would be to introduce an objectionable high-bar on reasonability. See footnote 19.
} 
in the literature..$^{25}$ Indeed, R-Decrease shares a certain parallel with how externalists tend to treat concrete cases that seem to favor internalism: they are cases that show that internalist factors can make one reasonable in changing one's degree of belief, but they cannot alter one's justification. ${ }^{26}$

\section{J-Immunity + R-Decrease $=$ Akrasia}

The problem with J-Immunity concerns its akratic implications. For it opens up the possibility of being lead into a kind of hypocritical situation where one fails to live up to ideals one reasonably believes one should live up to. This turns out to be a very good reason to reject J-Immunity.

To put an edge on the problem we'll derive a contradiction from JImmunity, R-Decrease, and two additional principles. The first concerns the relationship between doxastic justification and reasonability:

(J-R Entailment) If $S^{\prime}$ 's degree of belief in $\mathrm{P}$ is doxastically justified then $\mathrm{S}^{\prime}$ s degree of belief is reasonable.

This follows from the fact that doxastic justification involves the possession of genuine epistemic reasons, which, as discussed above, is sufficient for reasonability.

The second principle stands in opposition to doxastic hypocrisy:

(No R-Akrasia) One cannot (reasonably believe <that one has justification to believe $\mathrm{P}$ only to degree $\mathrm{n}>$, while reasonably believing $\mathrm{P}$ to a degree other than $n){ }^{27}$

By 'reasonably believe $\langle\ldots .$.$\rangle ', I mean something like 'has a very high reason-$ able degree of belief in $\langle\ldots .$.$\rangle '. There are plausible cases of 'akrasia' where$ one has a reasonable low or middling degree of belief <that they have justification to believe $\mathrm{P}$ only to degree $\mathrm{n}>$ while reasonably believing $\mathrm{P}$ to some degree other than $\mathrm{n}$. What's clearly problematic are cases where one's reasonable degree of belief in the higher order claim is very high, and one reasonably fails to conform to it. For simplicity, these qualifications are suppressed in what follows. ${ }^{28}$

\footnotetext{
${ }^{25}$ Ultimately, I think the epistemically problematic nature of d-etiological information is to be explained in terms of it being evidence of unreliability (cf. Vavova forthcoming) or some other form of epistemic risk. But these are substantive claims that I will not argue for here; R-Decrease is sufficient for present purposes.

${ }^{26}$ Section 5 will argue that the same problem facing advocates of J-Immunity also threatens externalists.

${ }^{27}$ Here and in what follows, $n$ may be taken to refer to either a specific credence or to a range of them. Thus if some form of permissivism about reasonability is true and this is permissive case for $S$, then $n$ refers to the range of credences that are reasonable for $\mathrm{S}$. Because of this, the problem to follow cannot be solved by adopting a version of permissivism.

${ }^{28}$ One referee pointed out to me that some might think facts about our psychological inabilities generate counterexamples to (No R-Akrasia). For instance, one might reasonably believe they have justification to believe $\mathrm{P}$ only to degree .865 , but realize that they're psychologically unable to believe anything to
} 
Anti-akratic theses along the lines of (No R-Akrasia) are common and have been endorsed and defended by others. ${ }^{29}$ This is unsurprising, for akrasia is a paradigmatic normative failing. Of course, the wrinkle in the present discussion is that I'm drawing a distinction between justification and reasonability, and not all who've defended anti-akratic principles have drawn this distinction or have drawn it in just the way that I have. But even so, defenses of anti-akratic principles have often been conducted in terms of some natural notion of 'rationality'. ${ }^{30}$ Accordingly, to the extent that my notion of reasonability maps onto that ordinary notion, those arguments can be co-oped in defense of (No R-Akrasia). ${ }^{31}$ Additionally, even if one were to reject (No R-Akrasia) by defending the idea that akrasia is sometimes reasonable, that will not be enough to avoid the problem to follow. One will further have to maintain that every time (i)-(iv) (below) are satisfied, the resulting akratic attitudes are reasonable. Those inclined to reject (No R-Akrasia) in such a startlingly strong and potentially ad hoc way can simply treat what follows as a defense of the conditional claim that if (No R-Akrasia) is true then a contradiction follows.

The contradiction depends on instances where each of the following hold:

(i) S has propositional justification to believe $\mathrm{P}$ only to degree $\mathrm{n}$-prior to as well as after gaining d-etiological information concerning her belief in $\mathrm{P}$.

such a fine degree. In such a case believing $\mathrm{P}$ to, perhaps, degree .86 or .87 seems reasonable. This potential counterexample, if sound, wouldn't threaten the overall argument against J-Immunity and JJImmunity. Advocates of anti-akratic theses could accommodate the idea that our psychological abilities (or reasonable beliefs about such abilities) are epistemically relevant by specifying that (No R-Akrasia), and related anti-akratic principles, hold in the range of circumstances where one is psychologically capable (or reasonably believes oneself to be psychologically capable) of bringing one's first-order beliefs and one's higher order beliefs into conformity. We could then run the reductio against J-Immunity and $\mathrm{JJ}$-Immunity in that context. The resulting attack on the immunity theses would be limited of course. It would have no impact on immunity theses that are limited to cases where one is (or reasonably takes oneself to be) psychologically incapable of bringing one's fist-order beliefs and one's higher order beliefs into conformity. But I doubt advocates of J-Immunity and JJ-Immunity would be attracted to a fall-back position that said, basically: only in cases where one is psychologically incapable of bringing one's fist-order beliefs and one's higher order beliefs into conformity does d-etiological information fail to defeat first- or higher order justification. So making (No R-Akrasia) sensitive to facts about one's psychological abilities would not significantly derail the argument against J-Immunity and JJ-Immunity.

${ }^{29}$ For defense of related anti-akratic principles, see Horowitz (2014), Sliwa and Horowitz (2016), Titelbaum (2015), Christensen (2010), Gibbons (2006, 32), Greco (2014), Goldman (1986), Feldman (2005), Bergmann $(2005,423)$, Smithies (2012), Scanlon (1998), and Littlejohn (forthcoming b). For recent opposition, see Greco (2014).

${ }^{30}$ Suppose one wanted to recast (No R-Akrasia) just in terms of blamelessness and leave it open as to whether there can be akratic cases of doxastic justification. To do so, one would have to reject the claim that doxastic justification entails blamelessness (see Section 2). For given that, any case of akrasia involving only doxastically justified beliefs will therefore also be a case of akrasia involving blameless beliefs. So if an anti-akratic thesis concerning blamelessness holds, so does a similar anti-akratic thesis concerning doxastic justification.

${ }^{31}$ Although some of the anti-akratic principles others endorse are wide-scope principles, it's arguably a short step from wide-scope anti-akratic principles to narrow-scope ones. See Lasonen-Aarnio (2015). 
(ii) Prior to gaining d-etiological information concerning her belief in $\mathrm{P}, \mathrm{S}$ 's doxastically justified degree of belief in $P$ was $n$.

(iii) $\mathrm{S}$ has a doxastically justified belief in (i) - prior to as well as after gaining d-etiological information concerning her belief in $\mathrm{P}$.

(iv) After, and in response to, gaining d-etiological information concerning her belief in $\mathrm{P}, \mathrm{S}$ decreased her degree of belief in $\mathrm{P}$ just slightly below $\mathrm{n}$.

Before deriving the contradiction, it is important to see that (i)-(iv) are jointly possible if $\mathrm{J}$-Immunity and $\mathrm{J}$-Immunity are true. (Those not worried about this can skip to the case called 'Two Dozen (or so) Theistic Arguments'.)

(i) is possible and consistent with (ii), (iii), and (iv) - provided they are also possible. (i)'s possibility is guaranteed if skepticism about propositional justification is false and J-Immunity is true. For if such a form of skepticism is false then it's possible to have justification to believe $\mathrm{P}$, and if J-Immunity is true then d-etiological information needn't defeat that justification. So (i) is possible. And, so long as (ii)-(iv) are also possible, (i) will be consistent with each of them. For, if (ii) is possible, (i) is consistent with (ii) because having propositional justification for $\mathrm{P}$ is consistent with having doxastic justification for $P$. And, if (iii) is possible, (i) is consistent with (iii) because it's possible to have propositional justification to believe $P$ to degree $n$ while having a doxastically justified higher order belief $<$ that one has justification to believe $P$ only to degree $n>$. Lastly, if (iv) is possible, (i) is consistent with (iv) since it's not a necessary condition on having justification to believe $\mathrm{P}$ to degree $\mathrm{n}$ that one actually believe $\mathrm{P}$ to degree $\mathrm{n}$. This is among the things that are supposed to distinguish propositional from doxastic justification: the former doesn't require a belief. Thus, if J-Immunity is true, we can conclude that (i) is possible and that (i) is consistent with (ii)-(iv) provided they are also possible.

(ii) is possible and is consistent with (iii) and (iv)-provided they are also possible. Unless a severe form of skepticism is true, (ii) is possible for it's just a claim about having doxastic justification in the absence of d-etiological information. Moreover, if (iii) and (iv) are possible, then (ii) will be consistent with each of them. (ii)'s consistency with (iii) is guaranteed by the fact that it's possible to have simultaneously justified beliefs in both first-order and higher order claims. (ii)'s consistency with (iv) is guaranteed by the fact that they are about one's attitude towards P in different circumstances: (ii) concerns one's attitude towards $P$ prior to gaining d-etiological information while (iv) concern's one's attitude towards $\mathrm{P}$ after gaining d-etiological information. Thus, (ii) is possible and, so long (iii) and (iv) are possibly true, (ii) is consistent with each of them. 
(iii) and (iv) are possible. (iii)'s possibility is guaranteed by J-Immunity. For J-Immunity implies JJ-Immunity (Section 1), ${ }^{32}$ which assures us that not only can one have justified higher order beliefs prior to gaining $d$ etiological information, but one can also have justified higher order beliefs afterwards. (iv) is possible since it's just a psychological claim about decreasing one's confidence in response to gaining d-etiological information. So (iv) is possible, and (iii) is possible if J-Immunity is true.

(iii) and (iv) are consistent. (iii)'s consistency with (iv) follows from two plausible claims. First, it's (logically and psychologically) possible for one to believe (i) while decreasing one's degree of belief in P. ${ }^{33}$ Second, having a weakened degree of belief in $\mathrm{P}$, as indicated by (iv), is consistent with one having a justified higher order belief in (i). For in at least those cases where (i) is true, one's weakened degree of belief in P is itself unjustified. And there is no motivation to maintain that unjustifiably believing $P$ to a degree just slightly less than $n$ necessarily defeats one's justified higher order belief <that one has justification to believe $\mathrm{P}$ only to degree $\mathrm{n}>.^{34}$ Thus, the conclusion to draw is that (iii) and (iv) are consistent. For they can both be true in at least those cases where one's weakened degree of belief in P is itself unjustified, which is just what (i) indicates. Put differently: one's justified higher order beliefs are not held hostage to one's unjustified first-order beliefs. Thus, not only are (iii) and (iv) consistent, but (i), (iii), and (iv) are consistent too.

(i)-(iv) are jointly possible. So, given J-Immunity, not only is (i)-(iv) each possible, but each pair involving (i)-(iv) is possible as well as the triple involving (i), (iii), and (iv). The other remaining triples give rise to no further concerns beyond those raised by their respective pairs.

Given this, we can safely conclude that (i)-(iv) are jointly possible if JImmunity and JJ-Immunity are true. For, recall, J-Immunity was needed to

\footnotetext{
${ }^{32}$ Suppose one were to reject this implication. This would not halt my argument. For all that's needed for it is that there be cases where instances of J-Immunity and JJ-Immunity both obtain, which is enough to generate possible cases in which (i)-(iv) obtain. So to effectively resist my argument at this point, one would have to argue for the thesis that there are no possible cases where instances J-Immunity and JJ-Immunity both obtain. But notice the cost of doing this is to maintain that either d-etiological information can defeat one's justification for first-order claims (in which case J-Immunity is false) or it can defeat one's justification for higher order claims (in which case JJ-Immunity is false). This strikes me as cold comfort for White and other advocates of J-Immunity. For I think an implicit part of White's paper is that we should not only think that first-order justification is immune to defeat by d-etiological information, but so is higher order justification. Moreover, if there are higher order defeaters, then defeat at the higher level can lead back to defeat at the lower level, which would challenge the idea that one could keep J-Immunity but reject JJ-Immunity. See footnote 29 for advocates of higher order defeat.

${ }^{33}$ This has occasionally been opposed. For a protracted defense see Chislenko (2016).

${ }^{34}$ For more on this kind of issue see Pryor $(2004,363-365)$. Note that Pryor's notion of rationality is a structural affair among one's beliefs and doesn't match my notion of reasonability. For more on how structural rationality may differ from other normative notions (like justification and reasonability) see Sylvan (2015b).
} 
show both that (i) was possible and that (iii) and (iv) are consistent, while JJImmunity was needed to show that (iii) was possible. So the joint possibility of (i)-(iv) crucially depends on these immunity theses.

Talking of situations where (i)-(iv) obtain is quite abstract. Let's make it more concrete by considering a case where (i)-(iv) would putatively obtain:

TWO DOZEN (OR SO) THEISTIC ARGUMENTS

Reggie is a theist who one day hears Alvin Plantinga give his lecture 'Two Dozen (or so) Theistic Arguments'. He understands the arguments, and does a commendable bit of research afterwards to satisfy himself that the premises involved in Plantinga's arguments are adequately justified. In this way Reggie comes to justifiedly believe in God's existence to a strong degree, and he also comes to justifiedly believe <that he has justification to believe that God exists to just that strong degree $>.{ }^{35}$ Time passes. Reggie eventually goes on to interact with many non-believers and comes by d-etiological information concerning his belief in God's existence (in the way described in the case called 'Religious Belief' above). But Reggie never obtains any reason to think the premises of Plantinga's arguments are defective. So Reggie retains his justified belief $<$ that he has justification to believe that God exists just to a strong degree>. Nevertheless, Reggie's d-etiological information troubles him, causing him to suspect that something other than his evidence 'lies behind' his belief that God exists. In response to this d-etiological information, Reggie's belief in God's existence weakens, falling slightly below the degree he takes himself to be justified in having.

Trouble comes when we ask after the reasonability of Reggie's decreased confidence in God's existence as well as the reasonability of Reggie's higherorder belief <that he has justification to believe that God exists just to a strong degree >. For it follows from (J-R Entailment) that Reggie's justified higher order belief is also reasonable. And, given R-Decrease, Reggie's weakened confidence in God's existence is reasonable too. But then it follows that Reggie reasonably believes $<$ that he has justification to believe that God exists just to a strong degree> while reasonably believing that God exists to a weaker degree. This contradicts (No R-Akrasia).

Notice that whatever one thinks of the case 'Two Dozen (or so) Theistic Arguments', reaching the contradiction does not depend on the intuitiveness of the case. There is no appeal here to intuitions about concrete cases. Rather the contradiction stems from the joint possibility of (i)-(iv) which were defended above. The case is just meant to be illustrative of what an instance of (i)-(iv) would look like. ${ }^{36}$

\footnotetext{
${ }^{35}$ I am assuming that in recognizing what reasons he had to believe God exists, Reggie was thereby gaining justification to believe <that he has justification to believe that God exists to just some strong degree>.

${ }^{36}$ Let me highlight a certain misunderstanding I've encountered about this case. Some have conveyed to me that it seems somehow problematic to think that Reggie could be reasonable in treating $\mathrm{d}$ etiological information as epistemically relevant to his first-order belief but not his higher order belief.
} 
So let me state in general terms how we can derive an explicit contradiction. Take a situation in which (i)-(iv) obtain. (ii) and (iv) ensure that the antecedent of R-Decrease is satisfied in cases where 'other things are equal'. So it follows from that and R-Decrease that S's decreased degree of belief in $P$, which falls just slightly below $n$, is reasonably held. From (iii) and (J-R Entailment) it follows that even after gaining d-etiological information $S$ reasonably believes (i), i.e. S reasonably believes $<$ that she has justification to believe $P$ only to degree $n>$. Thus, it follows that $S$ reasonably believes $<$ that she has justification to believe $P$ only to degree $n>$, while reasonably believing $\mathrm{P}$ to a degree other than $\mathrm{n}$. But this is contrary to (No R-Akrasia). Something has to give.

To summarize: (J-R Entailment), (No R-Akrasia), R-Decrease, and the joint possibility of (i)-(iv) entail a contradiction. R-Decrease, (J-R Entailment), and (No R-Akrasia) are well-motivated. So the best available response to the above reductio is to reject the joint possibility of (i)-(iv). But there are only two plausible ways to resist the joint possibility of (i)-(iv): deny $\mathrm{J}$-Immunity or deny JJ-Immunity. For these are the only two controversial and intuitively problematic assumptions that were made when showing that (i)-(iv) are collectively possible. J-Immunity was needed to show both that (i) was possible and that (iii) and (iv) are consistent, while JJ-Immunity was needed to show that (iii) was possible.

So we have reason to reject at least one of the immunity theses. However, it would be odd to reject J-Immunity without also rejecting JJ-Immunity since J-Immunity is the principal motivation for JJ-Immunity. So without JImmunity it's unclear what reason there would be to retain JJ-Immunity. Conversely, the rejection of JJ-Immunity would requires us to reject JImmunity provided J-Immunity implies JJ-Immunity (Section 1). Accordingly, a well-motivated strategy for dealing with the reductio is a unified one: reject both immunity theses. If both are false, then d-etiological information has a double impact concerning one's belief in P: it defeats one's justification to believe $P$ as well as one's justification to believe $<$ that one has justification to believe $\mathrm{P}>$. But even if one wanted to avoid the

Put differently, it's reasonable for Reggie to decrease his confidence in the first-order belief only if he also decreases his confidence in his higher order belief.

I feel the pull of this position, but I'm doubtful that one can take this position while hanging on to R-Decrease and the two immunity theses. For they jointly create space for one to reasonably reduce confidence in first-order claims without also reducing confidence in higher order claims. Still, for the sake of argument, assume that the worry is well-founded in contexts where R-Decrease and the two immunity theses hold. The key observation to make is that we can reach a contradiction even if Reggie were to decrease his confidence in the higher order claim. For, despite a reduction in confidence, it's possible that Reggie retain a very high degree of confidence in the higher order claim. Reggie just needs to be very, very confident in the higher order claim and to only slightly reduce his confidence in it. If that were his situation, we'd still run into trouble with (No R-Akrasia). 
above contradiction by rejecting only one of the two immunity theses, $\mathrm{d}$ etiological information would still be shown to defeat one's justification, be it first-order or higher order.

Given how defeat was characterized in Section 1, it follows that the immunity theses are false just in case d-etiological information can slightly reduce the degree of belief one is justified in holding. Since one can do that while still having a belief (albeit a weakened one), there will be the suspicion that we can reject the immunity theses while accepting White's broader point that d-etiological information never forces one to suspend belief. But this is not so. For if d-etiological information defeats justification, there will be a range of cases where one's original justified degree of belief was close enough to suspension that the addition of d-etiological information will require one to suspend belief. Granted, this is perhaps not Reggie's case. He has at least two dozen arguments for God's existence. But suppose he had only one argument or only arguments with weakly justified premises. Suspension might well be required of him.

\section{The extent and explanation of d-etiological defeaters}

I believe the least problematic and most intuitive response to the above contradiction is to take it as a reductio against J-Immunity and JJ-Immunity. Accordingly, I'm urging us to think that d-etiological information can defeat first- and higher-order justification. However, one might resist this way of solving the problem, thinking that White (2010) has adequately motivated J-Immunity (and hence JJ-Immunity). But this overestimates the strength of White's argument. White's primary argument for J-Immunity is an inference from absence, i.e. his defense of J-Immunity depended on the inability to locate a satisfactory reason for thinking that d-etiological information defeats justification. But the above reductio affords us clear motivation for thinking that d-etiological information does defeat justification. So for the immunity theses to stand we need some reason to think their rejection is not the best response to the above reductio.

So far I've only argued that the above reductio shows us that there are d-etiological defeaters. But how extensive are they? I've argued that what makes it the case that one loses justification when one gains d-etiological information in cases like Reggie's just is one's d-etiological information. If correct, the most natural view to take away from the above reductio and its suggested solution is this:

Extent: One has a d-etiological defeater for one's degree of belief in P and one's degree of belief <that one has justification to believe $\mathrm{P}>$ whenever one is in 
a position to reasonably reduce one's degree of belief in $\mathrm{P}$ in response to $\mathrm{d}$ etiological information. ${ }^{37}$

Anything more restrictive than this would need additional justification, specifying certain factors that have the power to undercut the defeating force of d-etiological information. Importantly, those undercutting conditions must be inconsistent with (i)-(iv), otherwise the proposed undercutting condition will allow the reductio to be re-introduced.

We can consider the search for such undercutting conditions as a search for a suitable replacement for $\phi$ :

$\phi$-J-Immunity: Provided $\phi$, gaining d-etiological information about one's belief that $\mathrm{P}$ cannot, all by itself, defeat one's justification to believe that $\mathrm{P}$.

Here are a couple of examples. According to Schoenfield (2013), d-etiological information does not defeat justification in permissive cases, i.e. cases where there is more than one justified response to the evidence. According to Elga (2008), d-etiological information does not defeat justification in cases of good governance, i.e. cases where one's d-etiological information fails to indicate that one has failed (or is likely to have failed) to be governed by their own epistemic standards in arriving at their belief. Thus, we can think of Schoenfield and Elga as inspiring something like:

Permissive-J-Immunity: Provided one is in a permissive case, gaining d-etiological information about one's belief that $P$ cannot, all by itself, defeat one's justification to believe that $P$.

Governed-J-Immunity: Provided one is in a case of good governance, gaining detiological information about one's belief that $\mathrm{P}$ cannot, all by itself, defeat one's justification to believe that P. ${ }^{38}$

But so long as one grants that it's reasonable to decrease confidence in one's belief that $P$ in response to d-etiological information in some permissive cases and some cases of good governance, we will be able to derive a contradiction from Elga's and Schoenfield's restricted J-Immunity theses just as we did from the unrestricted J-Immunity thesis we began with. For example, we could just further describe Reggie's case so that it's clear that he's in a permissive case and a case of good governance. That is, suppose that both Reggie and the atheists he's interacted with are in

\footnotetext{
${ }^{37}$ There is no tension between Extent and my admission in Section 1 that further information could neutralize the threat of d-etiological information. For the kind of etiological information gestured at there is information that would make it unreasonable for one to reduce one's degree of belief upon gaining d-etiological information.

${ }^{38}$ It has been pointed out to me that Schoenfield's and Elga's positions may not be that different. For Schoenfield endorses J-Immunity in permissive cases because, in those cases, an agent takes her own standards of reasoning (as opposed to other rational standards) to be the most truth-conducive. So, as long as she is confident that she has followed her own standards - that is, as long as it is a case of good governance in Elga's sense - she may maintain her belief.
} 
a permissive case: they are each justified in taking different positions on the existence of God; ${ }^{39}$ and, suppose Reggie has no reason to think he has not been living up to his own epistemic standards. There is nothing counterintuitive or inconsistent that results from augmenting the original descriptions of the Reggie case with these further additions. So it seems like there can be permissive cases and cases of good governance where (i)(iv) obtain. This is all we would need to re-run the reductio above against Permissive-J-Immunity and Governed-J-Immunity. Accordingly, if there is some way of restricting J-Immunity, it's at best unclear we've found it.

Notice that allowing d-etiological information to defeat justification doesn't have any problematic skeptical results. For permitting such defeat is consistent with the idea that we can, and typically do, retain justified beliefs upon gaining d-etiological information. For slightly decreasing one's confidence in accordance with a slight decrease in justification will not always, and perhaps will not typically, require one to reduce their confidence to the point of suspension of belief. Indeed, insofar as reducing one's belief to the point of suspension would be unreasonable in specific cases, (J-R Entailment) implies that it would be unjustified as well. So rejecting the immunity theses does not threaten to introduce any kind of skepticism. Rather it promotes a kind of epistemic modesty reflected in the idea that one ought to be less than fully certain when one becomes aware of the d-etiological origins of one's beliefs.

One question remains that I lack space to address. It's an explanatory question: why is it that d-etiological information defeats justification? I think the answer has to do with epistemic risk of some sort. D-etiological information is either information about some kind of unreliability (Vavova forthcoming; DiPaolo and Simpson forthcoming). But however one spells out the nature of the risk at issue, it should be clear that d-etiological information indicates that your responsiveness to your evidence was accidental in way that compromises its justification. ${ }^{40}$

\section{On the separability of positive epistemic properties}

In Section 3 we reached a contradiction. The contradiction followed from common epistemological principles together with the immunity theses and R-Decrease. The immunity theses told us d-etiological information will not impact justification; but R-Decrease told us that d-etiological information

\footnotetext{
${ }^{39} \mathrm{~A}$ possibility that Schoenfield herself defends.

${ }^{40} \mathrm{Again}$, no skeptical threat follows from this for d-etiological information only decreases one's justification, and it can do that without destroying it outright.
} 
will often impact reasonability. So holding R-Decrease and the immunity theses generates a separability claim:

(J-R Separability) It can be reasonable for one to believe $\mathrm{P}$ to degree $\mathrm{n}$ while lacking justification to believe $\mathrm{P}$ to degree $\mathrm{n}$.

Separability claims are all the rage in epistemology, and they have been for quite some time. For they generate a kind of elasticity in our theories of justification, allowing us to deal with putative counterexamples to our principles of justification.

This is nowhere more apparent than in the internalist/externalist debate. For decades, externalists have been claiming that putative internalist counterexamples to externalist theories of justification are not really counterexamples to externalism because they don't tell us anything about justification. ${ }^{41}$ Rather they tell us about the way internalist factors can affect the extent to which we are blameless ( $\approx$ reasonable) in shifting our beliefs in response to internalist factors.

But externalists who take this line of argument against internalists risk committing themselves to something like the following:

$R$-Decrease $e_{I F}$ : There are some internalist $f$ actors that can make it reasonable for a thinker to shift one's confidence in $\mathrm{P}$ below $\mathrm{n}$.

J-Immunity IF: Internalist factors cannot, all by themselves, defeat one's justification to believe that $P$.

$J$ J-Immunity IF: Internalist factors cannot, all by themselves, defeat one's justification to believe $<$ that one has justification to believe that $\mathrm{P}>$.

If J-Immunity $y_{I F}$ and JJ-Immunity $I_{\text {IF }}$ are a part of one's preferred externalist theory of justification, ${ }^{42}$ then it can be shown that internalist counterparts to (i)-(iv) will be jointly possible. ${ }^{43}$ And, just as we saw in Section 3, if such internalist counterparts of (i)-(iv) are jointly possible, then we can derive a contradiction from them together with R-Decrease $\mathrm{IF}_{F}$, (No R-Akrasia) and (J-R Entailment). To avoid contradiction, externalists who endorse RDecrease $_{I F}$, J-Immunity $y_{F}$, and JJ-Immunity ${ }_{I F}$ will have to reject either (No

\footnotetext{
${ }^{41}$ cf. Goldman (1988) and Littlejohn (forthcoming a).

${ }^{42}$ And it's hard to see how it couldn't be. For externalists want to forbid internalist factors from affording one justification, which seems to forbid internalist factors from defeating justification as well. For one to allow internalist factors to decrease the degree of justification one has to believe $\mathrm{P}$ (by defeating it) one would thereby have to allow such factors to increase the degree of justification one has to believe $\neg P$. (This is a very familiar and plausible part of Bayesian epistemology, but one needn't be a Bayesian to take the point.)

${ }^{43}$ Internalist counterparts to theses (i)-(iv) are theses that result from allowing internalist factors to play the role that d-etiological information plays in (i)-(iv). Just as we were able to show that (i)-(iv) were jointly possible if J-Immunity and JJ-Immunity were true, the internalist counterparts to (i)-(iv) can be

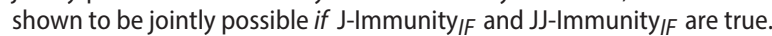


R-Akrasia) or (J-R Entailment). These are doubtless costs that will surprise many externalists. ${ }^{44}$

The point is not that (J-R Separability) is false. Rather, the point is that we cannot uncritically rely on its truth every time we need to explain away contrary intuitions. For the reductio of Section 3 shows us that the factors that make one reasonable cannot blithely be separated from the class of factors which make one justified when certain counterparts to R-Decrease, J-Immunity, and JJ-Immunity are in play.

\section{Acknowledgements}

Special thanks to audiences at Oxford University, the University of Canterbury, and to Michael Lynch for their contributions to this work.

\section{Disclosure statement}

No potential conflict of interest was reported by the author.

\section{References}

Alston, W. 1989. Epistemic Justification. Ithaca: Cornell University Press.

Ballantyne, N. 2012. The Problem of Historical Variability. Disagreement and Skepticism, Routledge Studies in Contemporary Philosophy, edited by D. Machuca, 239-259. New York: Routledge.

Bergmann, M. 2005. "Defeaters and Higher-level Requirements." The Philosophical Quarterly 55: 419-436.

Berker, S. 2013. "The Rejection of Epistemic Consequentialism." Philosophical Issues 23: 363-387.

Boghossian, P. 2008. Content and Justification. Oxford: Oxford University Press.

Cohen, G. A. 2000. If You're an Egalitarian, How Come You're So Rich? Cambridge: Harvard University Press.

Clarke-Doane, J. Forthcoming. Justification and Explanation in Mathematics and Morality. Oxford Studies in Metaethics. Oxford: Oxford University Press.

Chislenko, E. 2016. "Moore's Paradox and Akratic Belief." Philosophy and Phenomenological Research 92 (3): 669-690.

Christensen, D. 2010. "Rational Reflection." Philosophical Perspectives 24: 121-140.

Davis, J. 2009. "Subjectivity, Judgment, and the Basing Relation." Pacific Philosophical Quarterly 90: 21-40.

DiPaolo, J., and R. Simpson. Forthcoming. Indoctrination Anxiety and the Etiology of Belief. Synthese.

\footnotetext{
${ }^{44}$ Doubtless some externalists will reject anti-akratic constraints. But some do not. For instance, Goldman's (1986) reliabilism explicitly incorporates anti-akratic constraints $(1986,62)$. For other externalists friendly to anti-akratic constraints see Bergmann (2005), Plantinga (2000), and Littlejohn (forthcoming a).
} 
Elga, A. 2008. "Lucky to be Rational." Delivered at the 2008 Bellingham Summer Philosophy Conference.

Feldman, R. 2005. "Respecting the Evidence." Philosophical Perspectives 19: 95-119.

Feldman, R., and E. Conee. 1985. "Evidentialism." Philosophical Studies 48: 15-34.

Gibbons, J. 2006. "Access Externalism." Mind 115: 19-39.

Ginet, C. 2005. "Alston on Epistemic Justification." In Perspectives on the Philosophy of William P. Alston, edited by H. D. Battaly and M. P. Lynch, 37-54. Oxford: Rowman \& Littlefield Publishers.

Goldman, A. 1986. Epistemology and Cognition. Cambridge: Harvard University Press.

Goldman, A. 1988. "Strong and Weak Justification." Philosophical Perspectives 2: 51-69.

Greco, D. 2014. "A Puzzle About Epistemic Akrasia." Philosophical Studies 167: 201-219.

Horowitz, S. 2014. “Epistemic Akrasia." Nous 48: 718-744.

Lasonen-Aarnio, M. 2015. New Rational Reflection and Internalism about Rationality. Vol.

5. Oxford Studies in Epistemology. Oxford: Oxford University Press.

Littlejohn, C. 2012. Justification and the Truth-connection. Cambridge: Cambridge University Press.

Littlejohn, C. Forthcoming a. "Reasons and Theoretical Rationality." In The Oxford Handbook of Reasons and Rationality, edited by Daniel Star. Oxford: Oxford University Press.

Littlejohn, C. Forthcoming b. "A Plea for Epistemic Excuses." In The New Evil Demon, edited by F. Dorsch and J. Durant. Oxford: Oxford University Press.

Lord, E. Forthcoming. Epistemic Reasons, Evidence, and Defeaters. Oxford Handbook of Reasons and Normativity. Oxford: Oxford University Press.

Plantinga, A. 2000. Warranted Christian Belief. Oxford: Oxford University Press.

Pollock, J., and J. Cruz. 1999. Contemporary Theories of Knowledge. 2nd ed. New York: Rowman and Littlefield.

Pryor, J. 2001. "Highlights in Recent Epistemology." British Journal of the Philosophy of Science 52: 95-124.

Reynolds, S. 2013. "Justification as the Appearance of Knowledge." Philosophical Studies 163: 367-383.

Scanlon, T. 1998. What We Owe to Each Other. Cambridge: Belknap Press of Harvard University Press.

Schechter, J. 2008. "Luck, Rationality, and Explanation." Delivered at the 2008 Bellingham Summer Philosophy Conference.

Schoenfield, M. 2013. "Permission to Believe: Why Permissivism Is True and What It Tells Us About Irrelevant Influences on Belief." Nous 47: 193-218.

Schellenberg, J. 2007. The Wisdom to Doubt. Ithaca: Cornell University Press.

Sher, G. 2001. "But I could be wrong." Social Philosophy and Policy 18: 64-78.

Sliwa, P., and S. Horowitz. 2016. "Respecting All the Evidence." Philosophical Studies.

Smithies, D. 2012. "Moore's Paradox and the Accessibility of Justification." Philosophy and Phenomenological Research 85: 273-300.

Street, S. 2006. "A Darwinian Dilemma for Realist Theories of Value." Philosophical Studies 127: 109-166.

Sylvan, K. 2015a. "What Apparent Reasons Appear to Be." Philosophical Studies 172: 587-606.

Sylvan, K. MS. 2015b. "Rationality and Justification: Reasons to Divorce?" 
Titelbaum, M. 2015. Rationality's Fixed Point (or: In Defense of Right Reason). Oxford Studies in Epistemology. Oxford: Oxford University Press.

Vavova, E. Forthcoming. "Irrelevant Influences." Philosophy and Phenomenological Research.

Wedgwood, R. 2012. "Justified Inference." Synthese 189: 273-295.

White, R. 2010. "You Just Believe That Because." Philosophical Perspectives 24: 573-615. 